\title{
Retinopathy of Prematurity Stage 2 Intraretinal Ridge
}

National Cancer Institute

\section{Source}

National Cancer Institute. Retinopathy of Prematurity Stage 2 Intraretinal Ridge. NCI

Thesaurus. Code C99048.

An ophthalmoscopic finding that references retinopathy of prematurity characterized by the presence of an elevated ridge. 